\title{
Methodology for the Generation of Hydropedological Parameters Associated with Edaphic GIS Coverage and Databases for Hydrological Modeling ${ }^{\dagger}$
}

\author{
Antonio Luis Marques Sierra *, Nieves Roqueñí-Gutiérrez and Jorge Loredo-Pérez \\ Escuela de Ingeniería de Minas, Energía y Materiales. Universidad de Oviedo, Independencia 13, \\ 33204 Oviedo, Spain; nievesr@uniovi.es (N.R.G.); jloredo@uniovi.es (J.L.P.) \\ * Correspondence: marquesantonio@uniovi.es; Tel.: +34-985-104-294 \\ + Presented at the 2nd International Research Conference on Sustainable Energy, Engineering, Materials and \\ Environment (IRCSEEME), Mieres, Spain, 25-27 September 2018.
}

Published: 13 December 2018

\begin{abstract}
The long-term simulation of soil erosion and transport of contaminants and nutrients process in a river basin allows us to predict the impacts generated by the alterations of the environment and the scope of the potential contamination. The use of modeling tools such as SWAT (Soil and Water Assessment Tool) that integrates basin-level information on land use and management for hydrological simulation, requires specific data of soil and land use to define the Hydrological Response Units (HRU). These HRU are the basis of the simulation, grouping HRU according to hydrological response characteristics. The availability of quality data at the regional level is a key factor for obtaining robust models. One of the greatest shortcomings is found in obtaining hydropedological data bases associated with soil GIS shape.
\end{abstract}

Keywords: hydropedology; GIS; SWAT

\section{Introduction}

The hydropedological data used by the hydrological models can be divided into two groups that are grouped according to their characteristics: physical and chemical characteristics. The physical properties of the soil are those that govern the movement of water and air through the edaphic profile and have a greater impact on the water cycle within the HRU. Although the model necessarily requires physical properties, information on chemical properties is optional [1].

\section{Objectives and Methodology}

The objective is to generate a database of hydropedological parameters of the soils at regional level derived from the analytical data from the available soil profiles. The final result is a georeferenced complete database at regional level that can be used with hydrological models that require these data for its operation.

The workflow is divided into stages and is shown schematically in Figure 1. A first step is the collection of previous studies that contain datasets of edaphic profiles with sufficient parameters of soils to allow the calculation of the variables. From these data, the necessary variables for the SWAT database are calculated; The calculation of the properties of each edaphic profile of catchment under study is carried out by means of each of the variables by means of pedotranference functions that allow hydropedological parameters to be determined from edaphysical data $[2,3]$. 
At the same time, the existing cartography was georeferenced in physical format and digitalized. The Map of natural soils of Asturias [4] was used as a cartographic basis to link the SWAT soil type database, whose hydropedological parameters have been calculated for the basin, and the corresponding GIS coverage needed to calculate the HRU.

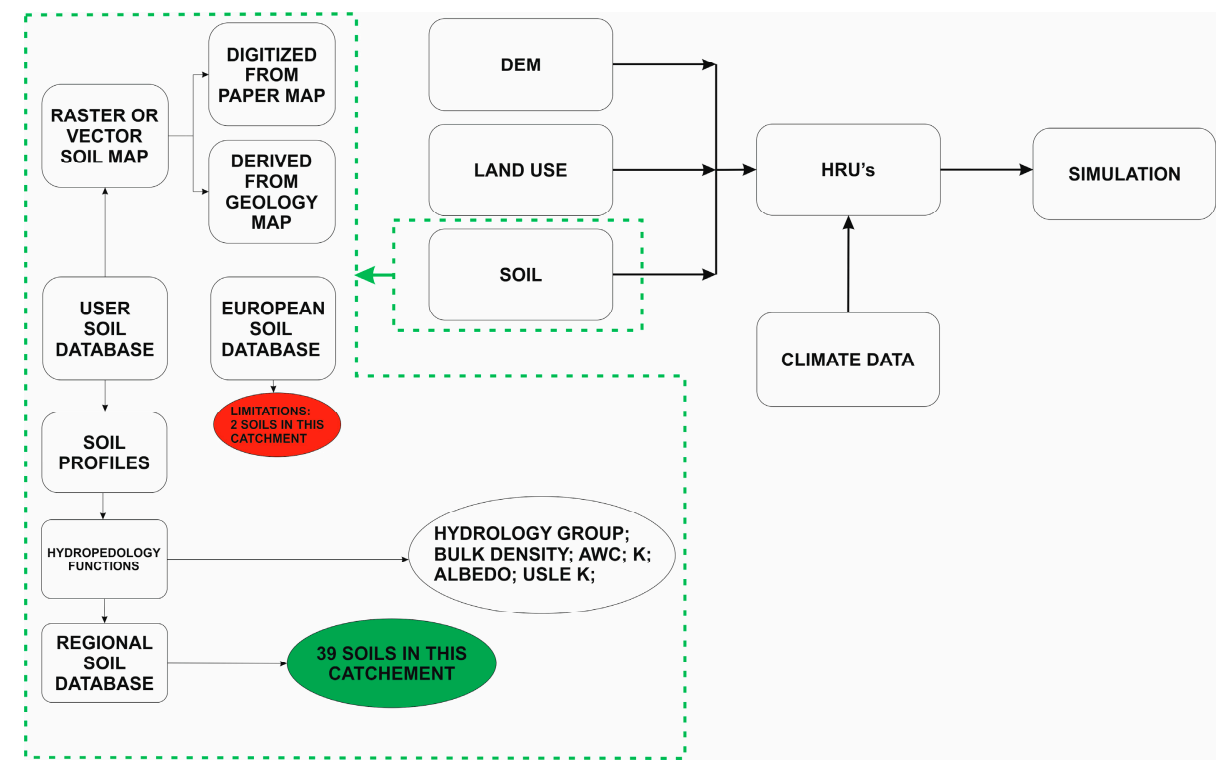

Figure 1. Workflow for the simulation in SWAT and in online points, workflow proposed in this work.

\subsection{Hydropedological Parameters}

For the determination of the hydropedological parameters of soils in Nalón river basin, the available soil profiles of Asturias were used. The work of the Institute of Agrobiological Research of Galicia (CSIC) that develops a detailed study of the natural soils of Asturias [4], together with the Soil Edaphological Properties Database of Spain (Volume II) developed by the Center for Energy, Environmental and Technological Research (CIEMAT) have been the basis of work.

Figure 2 shows the workflow with each soil profile, based on texture data of each soil, based on the available data [4]). The determination of SWAT parameters (density (BD), available water capacity of the soil layer (AWC), saturated hydraulic conductivity $(\mathrm{K})$ ) were realised using the formulation proposed by $[2,3]$.

CRK that define the maximum volume or potential cracks of the soil profile expressed as a fraction of the total volume of the soil. This parameter is used to predict surface runoff accurately in areas with a dominant proportion of Vertisols, the temporal change in soil volume must be quantified. The wet soil albedo, which is a measure of the ratio of the amount of solar radiation reflected by a body to the amount of radiation incident on it, expressed as a fraction, is another parameter to calculate. Albedo values are calculated when the soil is near or in field capacity. It can be calculated in different ways, but the simplest one is from a linear regression between albedo and the Chroma value of the Munsell color table for each soil profile by means of the expression. For cases in which a soil horizon lacks determination of the Munsell color value, 0.13 can be used as the default [1].

The soil erosion factor $(\mathrm{K})$ of the USLE equation must also be calculated by another formulation, in this case the one proposed by Williams (1995) which is the one recommended [1], although it can be calculated by several procedures [1]. 

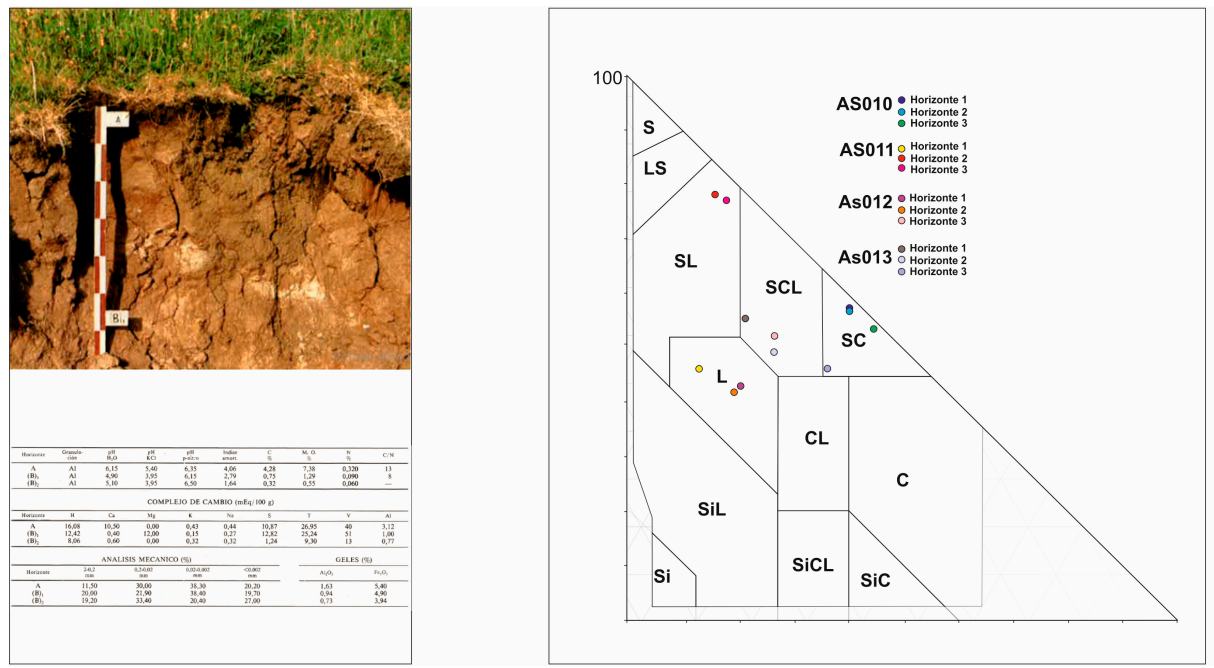

Soil data

Soil texture
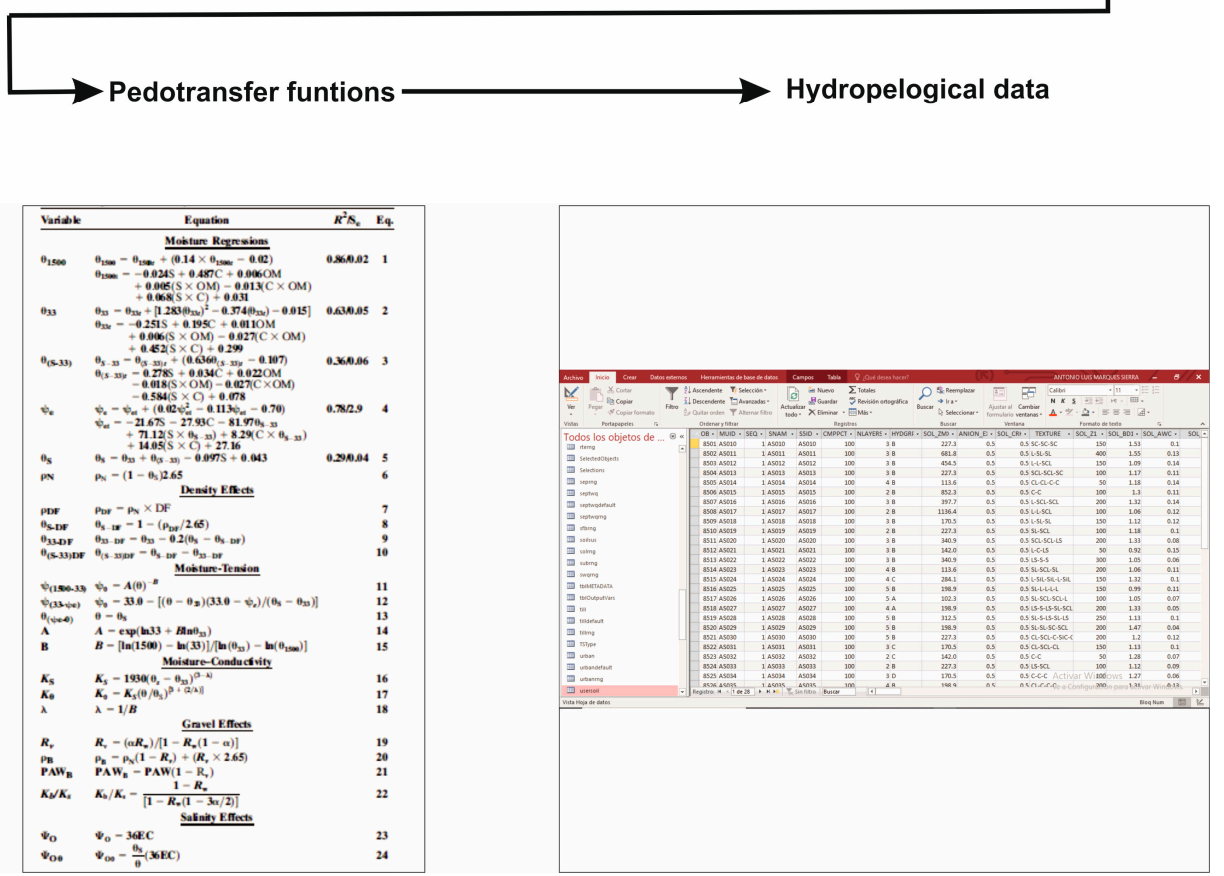

Figure 2. Methodology for hydropedology data determination for a single soil profile.

\subsection{Creating a GIS Soil Map}

The Map of natural soils of Asturias [4] was used as a cartographic basis to unite the SWAT soil type database, whose hydropedological parameters have been calculated for the basin according to the methodology described above, and the corresponding GIS shape necessary for the calculation of HRUs; Currently there is the only available cartography that has linked to each polygon that defines a soil profile with data that allow the calculation of hydropedological parameters.

The work process began with the conversion of the physical format to digital format. Subsequently, the georeferencing of the map was based on the provincial cartography 1:200,000. For the georeferencing process, the tool available in QGIS was used [5], with the result being that shown in Figure 3a. 


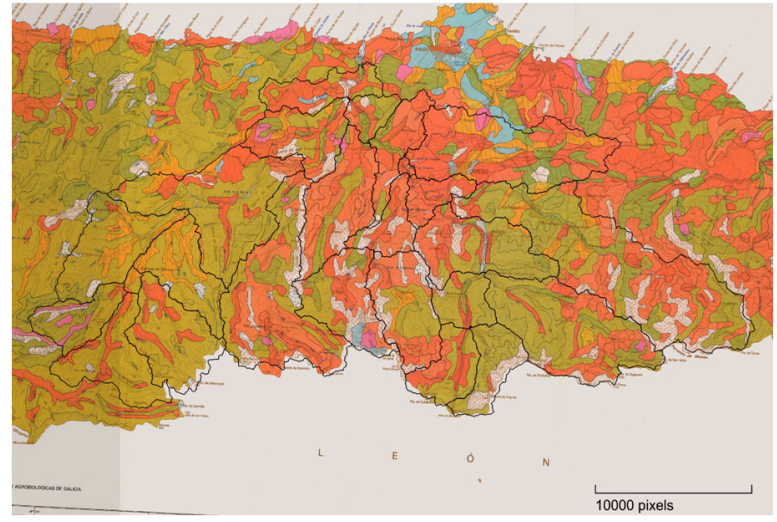

(a)

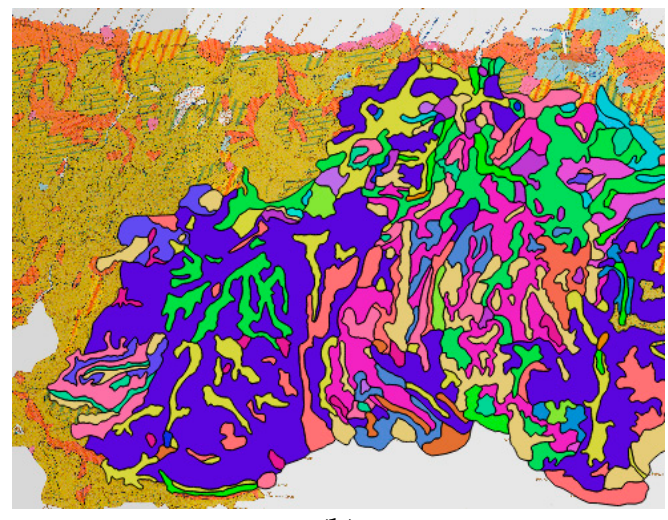

(b)

Figure 3. (a) referenced Soil map [4] and Nalon river basins; (b) Digitized Vector map of soils in Nalon Cachtment.

Once the raster file has been generated in * geotiff format, the polygons within the Nalón river basin have been digitized, with a buffer of $20 \mathrm{~m}$ on the outer profile of the basin to ensure that in the processes of HRU's generation, $100 \%$ coverage was achieved, the result is shown in Figure $3 \mathrm{~b}$. The initial database associated with the plane in *. Shp format, vector format, contained the ID, SNAM and SNAM85 codes. The ID is linked to each generated polygon, the SNAM code is the one designed to link the vector cartography with the SWAT database, while the SNAM85 code has been used to associate the codes consigned in the paper cartography with its corresponding in the SWAT database. This last code has been used to check the quality of the scanning process and the detection of errors in the code assignment.

\section{Results}

In total, 39 different soil profiles have been analyzed, spatially represented within the basin. The hydropedological database created at the regional level allows the association of polygons of soil coverage in a GIS environment for the creation of the HRU necessary for the generation of hydrological models. A summary of the statistics of the regional hydropedological database created is shown in Table 1 . The results show that $3.57 \%$ of the soils have only one horizon, while the percentage of soils with two or five horizons is of $21.43 \%$, three horizons in the soil is the most common in the basin with $42.86 \%$ of the cases; and finally, only $10.71 \%$ of the soils have four horizons. Horizon 1 is mostly sandy-silty, although there are two cases of clearly clay soils in this horizon. The horizon 2 presents mostly a sandy-clayey texture. The rest of horizons present textures like the two described as majorities in the previous horizons.

Regarding the apparent density, it is within the range of expected values, Table 1, except for the outlier that goes out of range. This value represents the apparent density of the rock outcrops. On the other hand, the value obtained from the pedotransference functions increases with depth, which is logical if we consider that when the depth increases, the compaction of the horizon increases [1].

The results allow to improve the sensitivity of the model to be the parameters calculated based on data obtained from edaphic profiles of the study area, which increases the geospatial representativeness of the database, compared to databases of large coverage where this data they are means for each type of soil and do not have to be like those of the area under study. This improvement results in the calculation of the HRU by having better starting data for the simulation process, and allows obtaining higher quality data for the calibration and validation processes.

An inherent limitation to the method used is the lack of a calibration process, which would require field measurements of the calculated variables of some type of soil, which would allow obtaining more precise estimated measurements for the rest of the soils. Another limiting factor is that soils with high clay content, greater than $60 \%$, do not offer satisfactory results [2]. 
Table 1. Summary of the statistics of the parameters calculated by horizons.

\begin{tabular}{ccccccc}
\hline Data & Mean & Median & Min & $\mathbf{1}^{\circ}$ Quart & $3^{\circ}$ Quart & Max \\
\hline BD1 & 1.2632 & 1.2 & 0.92 & 1.12 & 1.32 & 2.62 \\
BD2 & 1.3907 & 1.36 & 1.02 & 1.27 & 1.53 & 1.72 \\
BD3 & 1.469 & 1.48 & 1.19 & 1.37 & 1.55 & 1.73 \\
BD4 & 1.5278 & 1.49 & 1.32 & 1.4 & 1.6 & 1.8 \\
BD5 & 1.63 & 1.57 & 1.49 & 1.53 & 1.8 & 1.86 \\
AWC1 & 0.0996 & 0.11 & 0.01 & 0.08 & 0.13 & 0.15 \\
AWC2 & 0.103 & 0.1 & 0.01 & 0.06 & 0.11 & 0.5 \\
AWC3 & 0.0743 & 0.06 & 0.01 & 0.05 & 0.11 & 0.14 \\
AWC4 & 0.0844 & 0.07 & 0.03 & 0.06 & 0.12 & 0.15 \\
AWC5 & 0.0783 & 0.06 & 0.04 & 0.05 & 0.11 & 0.15 \\
K1 & 40.1768 & 26.23 & 0.01 & 9.89 & 70.33 & 144.66 \\
K2 & 32.4115 & 8.52 & 0.41 & 3.02 & 23.28 & 271.25 \\
K3 & 24.2967 & 3.22 & 0.01 & 0.46 & 20.16 & 134.92 \\
K4 & 7.3256 & 3.82 & 0.15 & 0.61 & 8.81 & 25.75 \\
K5 & 10.055 & 6.18 & 0.24 & 1.27 & 8.81 & 40.84 \\
ALB1 & 0.1595 & 0.162 & 0.024 & 0.093 & 0.231 & 0.3 \\
ALB2 & 0.2233 & 0.231 & 0.024 & 0.162 & 0.3 & 0.438 \\
ALB3 & 0.2561 & 0.231 & 0 & 0.162 & 0.369 & 0.438 \\
ALB4 & 0.2847 & 0.3 & 0.162 & 0.231 & 0.369 & 0.369 \\
ALB5 & 0.323 & 0.3 & 0.231 & 0.3 & 0.369 & 0.438 \\
USLE_K1 & 0.4848 & 0.525 & 0.001 & 0.4632 & 0.6069 & 0.6811 \\
USLE_K2 & 0.4838 & 0.5148 & 0.1691 & 0.4584 & 0.5417 & 0.7889 \\
USLE_K3 & 0.4503 & 0.479 & 0.1995 & 0.2565 & 0.549 & 0.7973 \\
USLE_K4 & 0.481 & 0.4756 & 0.2599 & 0.3974 & 0.6238 & 0.6983 \\
USLE_K5 & 0.5755 & 0.607 & 0.2732 & 0.3412 & 0.669 & 1.1386 \\
\hline & & & & & &
\end{tabular}

\section{References}

1. Arnold, J.; Kiniry, J.R.; Srinivasan, R.; Williams, J.R.; Haney, E.B.; Neitsch, S.L. Soil and Water Assessment Tool "SWAT"; Texas Water Resources Institute: College Station, TX, USA, 2012; doi:10.1007/978-0-38735973-1_1231.

2. Saxton, K.E.; Rawls, W.J. Soil Water Characteristic Estimates by Texture and Organic Matter for Hydrologic Solutions. Soil Sci. Soc. Am. J. 2006, 70, 1569-1578. doi:10.2136/sssaj2005.0117.

3. Saxton, K.E.; Rawls, W.J.; Romberger, J.S.; Papendick, R.I. Estimating generalized soil-water characteristics fom texture. Soil Sci. Soc. Am. J. 1986, 50, 1031-1036.

4. Guitian Ojea, F.; Muñoz Taboadela, M.; Carballas Fernandez, T.; Alberto Jimenez, F. Suelos Naturales de Asturias; CSIC: Santoago de Compostela, Spain, 1985; p. 122.

5. QGIS Development Team, 2009. Available online: http://www.qgis.org/ (accessed on 17 February 2015).

(C) 2018 by the authors. Licensee MDPI, Basel, Switzerland. This article is an open access article distributed under the terms and conditions of the Creative Commons Attribution (CC BY) license (http://creativecommons.org/licenses/by/4.0/). 